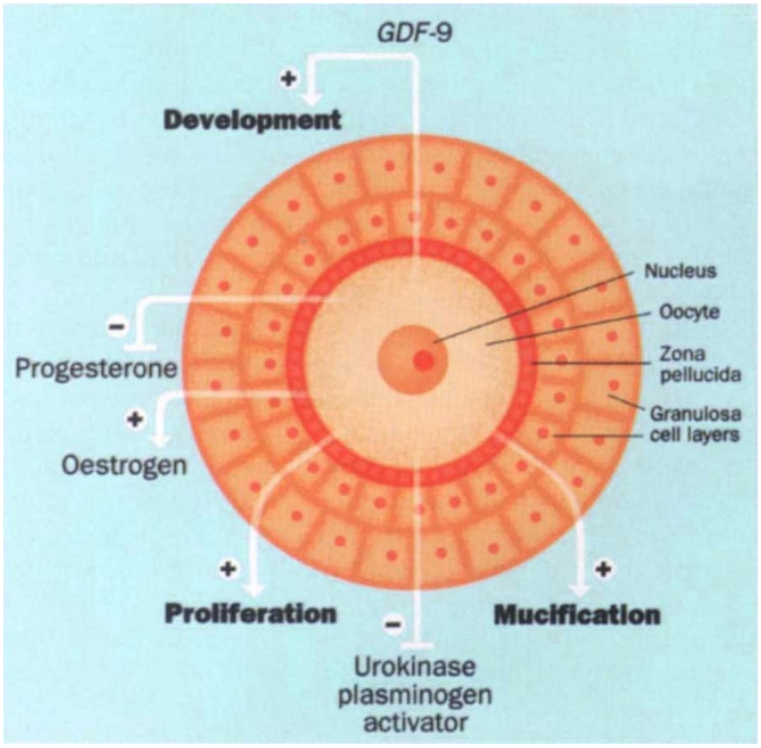

FIG. 2 The oocyte secretes a number of factors (not necessarily simultaneously) that influence the surrounding granulosa cells and their ability to respond to follicle-stimulating hormone. Dong et al. ${ }^{2}$ have now identified GDF-9, an oocyte-derived factor that is required for somatic cell development in vivo.

longer secrete hyaluronic acid in response to FSH or cyclic $\mathrm{AMP}^{5}$, at least in mouse ovaries. So they fail to produce a sticky mucinous mass that can be picked up after ovulation by the ciliated entrance to the fallopian tube. What is more, as well as the so-called 'cumulus-expansion-enabling factor', oocytes secrete something that helps to prevent the breakdown of the extracellular matrix by inhibiting the production of urokinase plasminogen activator ${ }^{6}$. Oocytes also stimulate the proliferation of granulosa cells throughout the course of follicle growth. After oocyte removal, cultured granulosa cells from small follicles and cumulus masses from large ones cannot incorporate as much tritiated thymidine as can intact controls ${ }^{7}$, and are growth-retarded as a consequence. Such findings are reminiscent of the morphology of polyovular follicles in which each oocyte can induce the formation of its own mound of cumulus cells.

But the quest to isolate and identify the factors responsible for these phenomena has been frustrating, perhaps because they are rapidly degraded under culture conditions. Nevertheless, the experimental evidence leaves little doubt that several factors are involved. And because granulosa cells respond to an oocyte-conditioned medium in a concentration-dependent manner, and they do not require physical contact with the oocytes, the active agents are evidently secreted, rather than simply being passed from cell to cell through gap junctions.

Dong et al. have now shown ${ }^{2}$ that a specific oocyte product, growth differentiation factor-9 (GDF-9), is required for the development of granulosa cells (Fig. 2). Targeted deletion of this member of the transforming growth factor- $\beta$ superfamily using embryonic stem-cell technology, leads to sterility in homozygous female mice $\left(g d f 9^{\mathrm{m} 1} / g d f 9^{\mathrm{m} 1}\right)$ - in contrast, homozygous males are normally fertile. The defect is independent of the expression of FSH, luteinizing hormone or activin type-II receptors, and reveals that the primaryfollicle stage is a critical transition in development. Oocytes in mutant mice grow and secrete a zona pellucida, but follicles form only one layer of granulosa cells and the theca fails to differentiate. The gonads remain diminutive and, as a result of weak secretory activity, serum gonadotrophin levels rise and encourage the growth of ovarian cysts.

What, if anything, is the practical significance of these findings? For one thing, GDF-9 may help to overcome deficiencies in follicleculture technology. There is even a slim chance that it will turn out to be the aforementioned mucification factor, although there is evidence against this view ${ }^{8}$. The GDF-9 knockout mouse could also become a useful model for clinical pathology. Resistant-ovary syndrome is a heterogeneous disorder of early follicle development in women, and in some cases it could be due to a deficiency in GDF-9. One thing is clear - GDF-9 is unlikely to have much impact on the rate of follicle attrition during ageing, because it acts downstream of the primordial stage in which follicles are stored pending recruitment for growth. But the discovery of the dramatic effects of this gene will encourage more efforts to identify other oocyte-derived factors affecting follicle development. This could throw fresh light on unexplained forms of infertility and indicate new strategies for contraception.

Roger Gosden is at the Centre for Reproduction, Growth and Development, University of Leeds, Division of Obstetrics and Gynaecology, Clarendon Wing, Leeds General Infirmary, Leeds LS2 9NS, UK.

1. Buccione, R., Schroeder, A. C. \& Eppig, J. J. Biol. Reprod. 43, 543-547 (1990)

2. Dong, J. et al. Nature 383, 531-535 (1996).

3. El-Fouly, M. A., Cook, B., Nekola, M. \& Nalbandov, A. V. Endocrinology 87, 288-293 (1970).

4. Vanderhyden, B. C., Cohen, J. N. \& Morley, P. Endocrinology 133, 423-426 (1993).

5. Buccione, R., Vanderhyden, B. C., Caron, P. J. \& Eppig, J. J. Dev. Biol. 138, 16-25 (1990).

6. Canipari, R., Epifano, O., Siracusa, G. \& Salustri, A. Dev. Biol. 167, 371-378 (1995)

7. Vanderhyden, B. C., Telfer, E. E. \& Eppig, J. J. Biol. Reprod. 46, 1196-1204 (1992).

8. Vanderhyden, B. C., Caron, P. J., Buccione, R. \& Eppig, J. J. Dev. Biol. 140, 307-317 (1990).

\section{Eschewing the fat}

THE British government has set a target for reducing obesity. In effect, the nation is being collectively asked to shed about 20,000 tons of fat by 2005 . Progress so far has been negative.

Obesity seems to start in childhood, when our fat cells readily multiply. Thereafter they are always ready to be filled, and rapidly undo the most dedicated slimming efforts. Liposuction can remove them permanently, of course; but a government liposuction initiative would not be popular. Musing on the problem, Daedalus recalled that the anaesthetic gas nitrous oxide is over five times more soluble in fat than it is in water. Hence its use as a blowing agent in aerosol cans of whipped cream. So if you pressurized an obese patient in nitrous oxide, the gas would dissolve preferentially in his fatty tissue. If the pressure were suddenly released, it would bubble out of solution. His fat cells, loaded with dissolved gas, would swell up and burst. His other cells, containing very little fat, would be unaffected.

This, of course, is a form of 'the bends', that painful syndrome felt by a diver who comes up from deep water too quickly. DREADCO's 'fat-bending chamber' will minimize this discomfort. Its content of oxygen and nitrous oxide will anaesthetize the subject during decompression. The smallest feasible pressure-drop will be used, probably from somewhat above normal pressure to somewhat below it, so as to destroy only a small fraction of the subject's fat cells. Their broken fragments and freed fat will be released into the body; it may take a few days for the liver and the body's scavenging systems to dispose of this detritus. The subject can then have a further session. For the government mass health programme, Daedalus is designing a mobile collective fat-bending chamber, a sort of pressurized bus to tour obesity troublespots, and in which dozens of people can have their fat bent away simultaneously.

Cosmetic fat-bending poses trickier problems. How to remove unwanted fat, while leaving more desirable deposits untouched? Daedalus recalls the old technique of 'cupping' - reducing the pressure over a small area of the skin by a sort of suction bell-jar. He plans to develop it into a controllable, local method of fat-bending. The patient would be anaesthetized with nitrous oxide; then in slow, carefully judged stages, fat would be cupped away from the regions of excess. The client would slowly acquire the figure of his or her dreams. It would be permanent: stable against the most wanton bingeing. The fat cells which might store the deadly calories would simply no longer be there. David Jones 